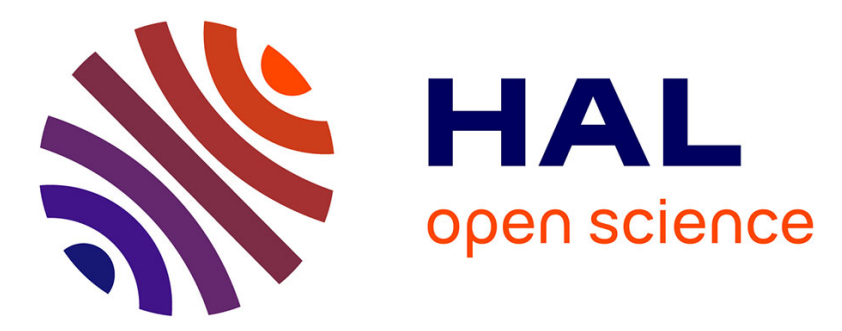

\title{
The Turning Point: MEP Contractors as the Key to Achieving Lifecycle BIM
}

\author{
Sumit Oberoi, Dominik Holzer
}

\section{To cite this version:}

Sumit Oberoi, Dominik Holzer. The Turning Point: MEP Contractors as the Key to Achieving Lifecycle BIM. 11th IFIP International Conference on Product Lifecycle Management (PLM), Jul 2014, Yokohama, Japan. pp.83-90, 10.1007/978-3-662-45937-9_9 . hal-01386478

\section{HAL Id: hal-01386478 https://hal.inria.fr/hal-01386478}

Submitted on 24 Oct 2016

HAL is a multi-disciplinary open access archive for the deposit and dissemination of scientific research documents, whether they are published or not. The documents may come from teaching and research institutions in France or abroad, or from public or private research centers.
L'archive ouverte pluridisciplinaire HAL, est destinée au dépôt et à la diffusion de documents scientifiques de niveau recherche, publiés ou non, émanant des établissements d'enseignement et de recherche français ou étrangers, des laboratoires publics ou privés. 


\title{
The Turning Point: MEP Contractors as the key to achieving lifecycle BIM
}

\author{
Sumit Oberoi and Dominik Holzer
}

Air Conditioning and Mechanical Contractors' Association (AMCA), AUSTRALIA

The University of Melbourne, AUSTRALIA

\begin{abstract}
Developments in the construction industry across a number of countries over the past decade suggest that the use of Building Information Modeling (BIM) is becoming the norm for the design and delivery of projects. As BIM increasingly enters a broad range of domains within the built environment, the importance of Specialist Contractors - and in particular MEP Contractors - as part of these developments begins to show. MEP Contractors form a crucial link in the information-chain to achieve life-cycle BIM. This paper investigates the shift to the role of MEP Contractors in the context of BIM. It analyses the structural changes within the contracting professions, and it highlights the impact of BIM enabled MEP Contractors on the construction industry as a whole. The paper scrutinises this development by example of the BIM-MEP ${ }^{\mathrm{AUS}}$ initiative of the Australian Air Conditioning and Mechanical Contractors' Association (AMCA). Accounts from BIM-MEPAUS illustrate the raise of the BIM-enabled MEP Contractors and thereby act as a reference for other international industry groups who may wish to follow their example.
\end{abstract}




\section{Background to the use of BIM in the construction industry}

Research suggests that the construction industries in a number of developed countries waste some 30 per cent of their efforts through rework and inefficient practices [1] [2]. If that wasted effort were to be reduced, it would make a significant contribution to the construction industry's environmental footprint globally. If the changes required to achieve that reduction were also to flow throughout the supply chain then the improved output would be substantially higher. Embracing the ethos at the core of Integrated Project Delivery (IPD) ${ }^{1}$ practices, modelling techniques and supply chain integration practices have proven to be pivotal for a number of industries to achieve notable productivity gains within the past forty years [3].

Although the use of BIM technology in the delivery of construction project is now becoming pervasive, significant fragmentation and adversarial business models in the construction sector have prevented efficiency-gains to translate across the entire building life-cycle [4]. The predominant project-focus prevailing in the construction industry is creating impediments to innovation as ongoing projects do not incorporate systemic efforts towards innovation through rigid organisation practices [5]. The construction industry is consistently slow in adopting new project management and workflows practices that leverage technological advancements; in parallel, the manufacturing sector is also experiencing a decline ${ }^{2}$. Whilst the low productivity in the building sector can be partly attributed to the "one-off or bespoke" nature of construction activities with each project being essentially a prototype, there is a lack of focus on process improvement and collaborative integrated project delivery practices. BIM can bridge this gap, as the platform for construction innovation and specify a focus on process improvement and collaboration. Organisations such as buildingSmart alliance and the US National Institute of Building Sciences have been promoting the uptake of BIM and related technology since the mid-1990s, other industry bodies and institutes have followed their lead.

\footnotetext{
${ }^{1}$ IPD was first introduced by the California Council of the American Institute of Architects (AIA|CC) in 2007 as part of a publication tiled: Integrated Project Delivery: A Working Definition. A comprehensive summary of IPD principles can be found as an online resource by the AIA|CC: http://www.aiacc.org/2012/06/05/integrated-project-delivery-a-history-of-leadershipadvocacy-and-commitment/

${ }^{2}$ As an example: Over the past 25 years, Australia's manufacturing sector's share of total industry gross value added (GVA) has declined from 16 per cent in the year to the June quarter 1986 to 10 per cent in the year to the June quarter 2011; Source: Trends in manufacturing to 2020, Future Manufacturing, Department of Innovation, Industry, Science and Research, Australia
} 
Key organisations in the propagation of BIM within construction sectors globally have been the U.S. General Services Administration - mandating BIM for Spatial Program Validation on their projects since 2006 [6] and the 'Department of Veterans Affairs' (releasing a BIM Guide [7] in 2010) . In the UK, the National BIM Task Group has continuously been working on policies for the introduction of BIM on public sector projects. This combined industry/government funded organisation has laid out a roadmap for a gradual introduction of BIM requirements for projects procured via central government departments between 2011 and 2016 (\& beyond). The Singaporean Building and Construction Authority (BCA) introduced an e-submission system for regulatory submissions based on BIM data back in 2008. The above examples merely represent the tip of the iceberg of recent industry/government initiatives to propagate BIM.

One notable aspect reflected in most of the approaches by the above industry bodies and organisations is their focus on BIM for architects and engineers. These consultants were the first to integrate BIM into their profession-specific work processes. Hence, BIM software initially mainly catered for architectural and engineering processes. A recent global industry study [8] points in the direction that, after several years of moderate change, Contractors are currently the most active industry group in adopting BIM. Annual growth rates in BIM uptake among Specialist Contractors in particular are excelling in a great number of industrialised countries. What influence has such transition on the required expertise and BIMrelated capabilities by Specialist Contractors? How do associated industry bodies react to this challenge? How do they adopt their training regimes to foster BIM?

\section{The changing skill requirements for Specialist Contractors}

Specialist Contractors in most developed countries are undergoing a major transition in their education from 2D drawing to object based 3D modelling. Current and novice professionals undergo dedicated BIM training as industries gears up to become BIM enabled [9]. A pivotal part of this education process is BIM advocacy and stronger awareness of the change in work practices by major industry bodies. Implementing BIM is more than picking up software skills; it is about acquiring communication and collaboration skills that enable and encourage stakeholders across the building life-cycle to deliver projects in an integrated way [9].

For Specialist Contractors this process-change means: preparing for early involvement in the design process and interpreting consultants' BIM for the purpose 
of creating BIM equivalent to the level of resolution inherent to traditional a shop drawings. Such translation requires prior definition of standards for information exchange and the generation of BIM content in order to comply with technical schedules. Research and Development into standard forms of information exchange between collaborators has been high on the list of organisations such as the buildingSmart alliance. Their Industry Foundation Classes (IFC2 $\times 4$ ) format allows for the transfer of data-rich 3D models from one software platform to another (with little loss of data fidelity). At the same time the 'Construction Operations Building information exchange' (COBie), created by the U.S. Army Corps of Engineers and NASA [10], is developed as a standard framework of objects for information exchange to link construction data to facility management in a structured manner.

It becomes crucial to associate BIM components on a Specialist Contractor level with numeric product data (quantities, cost, servicing), to consider interfaces to computer aided manufacture (CAM) for rapid ( \& less waste) manufacture, and to facilitate the generation of O\&M manuals that can be accessed by a facility's operator [11]. The Specialist Contractor can therefore advise the Facility/Asset Manager on how the Commission As-Built (CAB) will influence the operation of the building. Specialist Contractors who form part of this 'information supply chain' need to be more encompassing in terms of the tasks they are able to facilitate [11]. Depending on the project type, MEP equipment constitutes approximately $15-25 \%$ of construction cost [12]. Such numbers highlight the relevance of the work undertaken by the MEP Contractors in particular. MEP Contractors rely on a combination of 'Made-to-stock' and 'Engineered-to-order' components [13]. Whereas the former can usually be grouped and represented in an electronic product catalogues, the latter group requires specialist assembly and installation. Appropriating product information from MEP Contractors hence requires diligent mapping of production information and performance specifications. Further, MEP Contractors deal with process-planning and the sequencing of fabrication and assembly activities on and offsite, with substantial risk associated to estimating correct quantities and workloads for costing purposes [14].

\section{Information-richness associated to MEP Contractor BIMs}

The level of detail and precision Specialist Contractors and trades apply to design for fabrication is unparalleled compared to other parties involved on construction projects. The ConsensusDOCS 301BIM Addendum by the Associated General 
Contractors of America (AGC) BIM Forum [15] provides a clear distinction in definition between 'Design' and 'Construction' BIM.

Design BIMs contain the design/procurement/CAB (commissioned as built) technical schedules and provides a basic range of standard generic design models covering the major requirements of the designer's. Design data embedded in the BIM objects that are compiled during the design development stage includes the extraction of specification relevant data for the equipment schedules as well as system integration information. In current practice, there still remains room for improvement regarding the usefulness of Design Intent BIM passed on by some consultants to other stakeholders such as the Specialist Contractor [16]. There exists one related factor that impacts on an industry's ability to achieving life-cycle BIM: The lack of standardised BIM object libraries that facilitate the dialogue between consultants and those further down the supply-chain.

Construction BIMs on the other hand are manufacturer specific models which have both the design schedule and procurement schedule data completed. Models are dimensionally accurate sufficient for workshop detail drawings for manufacturing and installation purposes. In addition to their role as translators, MEP Contractors are also responsible to attach product details (data-sheets) for Operation and Maintenance (O\&M) manuals associated to the geometrical information in BIM. Construction BIMs also need to consider the installation constraints and safe handling sequencing, as well as the spatial requirements for access and servicing during operation. In doing so, MEP Contractors link equipment information from construction to operation and maintenance; the abovementioned COBie format is one pathway to achieve such links. These 'as-maintained' BIMs can be accessed via the cloud and viewed on tablet devices that can extract the data on demand [9].

\section{Responding to the Challenges: The BIM-MEP ${ }^{\mathrm{AUS}}$ Initiative}

Industry bodies representing Specialist Contractors and the trades have a responsibility to assist their members in mastering the transition to BIM. In this paper, the authors focus on the approach taken by the Australian 'Air Conditioning and Mechanical Contractors' Association' (AMCA) to support the development of bespoke standards and BIM content for their members through their initiative: 'BIMMEPAUS, 
The BIM-MEP ${ }^{\mathrm{AUS}}$ initiative by the AMCA was started in early 2010 with the goal to investigate steps to introduce a 'BIM-all-the-way' life-cycle workflow to their constituency. The initiative started by conducting targeted research surveys among 15 of its key members across all Australian states. Based on their qualitative feedback, a discussion paper was released that led to the formation of a combined industry/academia steering committee consisting of 25 Australian BIM/MEP Contractor experts. Representatives of the BIM Steering Committee included representation from specialist building services contractors, consultants, architects, builders, equipment manufacturers and suppliers, and software vendors.

Targeted research by the BIM-MEPAUS initiative identified a number of challenges related to the role of MEP Contractors in the context of life-cycle BIM: Participants in their research lamented the inadequate information content within 'Design BIMs' that were not set up with their estimating, fabricatable, installation and maintenance needs in mind by consultants. A trend is noticeable among mechanical Specialist Contractors: They increasingly take over modelling tasks that were traditionally performed by engineering drafters who would provide more than just the performance outline, scope of works and design intent of uncoordinated services routes and equipment to be installed.

Further, the BIM-MEPAUS research revealed that the lack of standardisation within a number of construction industries has created barriers to the effective uptake and use of BIM. Concerns about the viability of BIM remain among a large number of MEP Contractors irrespective of a particular discipline; specific concerns include:

- Significant time and cost burden involved in customising BIM modelling software to suit both design and construction requirements.

- Lack of industry standards supporting BIM.

- Inconsistent interoperability between different BIM software packages.

- Poor consideration of the requirements for integrated project delivery.

- Limited BIM project and data management expertise within the industry.

- Reluctance to share the models by consultants and other trades.

- Not enough time allowed with Specialist Contractors to engage earlier.

- Client expectations of BIM for ongoing O\&M are often not understood well.

- Consultants not educated to understand the fabricateable, installation and maintenance site constraints. 


\section{Bridging between 'Design Intent BIM' and 'Construction BIM'}

In direct response to the challenges mentioned above, the BIM-MEPAUS initiative proposes a 'BIM-all-the-way' design/construction/ (CAB) workflow. The BIMall-the-way workflow enables a building to be designed and coordinated in a virtual environment before being built on site whilst also allowing best of breed fabrication software to be used for the manufacture and estimating. The workflow is fundamentally dependent on the use of managed content to deliver standard models which are certified to assure compliance with the technical schedules and functionality with the BIM-MEPAUS add-in for BIM authoring software and fabrication software needed for manufacturing purposes and for procuring bought in equipment. There exists a range of opportunities for supplier-interaction amongst various businesses that link project components from various MEP Contractors together during off site assembly processes called modularisation for 'just in time' site deliveries.

The BIM-MEPAUS approach can be adjusted to suite other trade contractors and their specific workflow. The combination of strong standards in parallel with the development of referring BIM content facilitates a fluid transition from the design phase to the construction phase, and ultimately to the fabrication phase. The following paragraphs highlight how this transition is currently facilitated through BIM-MEP ${ }^{\mathrm{AUS}}$.

Design phase

Manufacturers should be able to promote vendor neutral 'Design' BIMs related to their respective trade (ideally hosted on an online repository). Examples of where this is likely to occur are where a new product is introduced into the market.

Where a manufacturer works with a designer/detailer, they would ideally have access to a framework for certification by their respective industry body. This should allow manufacturer models to be inserted in the design model. The design schedules generated will identify the manufacturer as either a nominated supplier, or approved or equal supplier as deemed appropriate by the designer.

Construction phase

Once the key structural elements are determined and the 'Design' is clearly defined at the end of Design Development, it is envisaged that the trade installers will take custodianship of certified BIM components and will develop them to 'Construction BIM' model status, which will: 
- incorporate the manufacturer models for the equipment selected;

- sufficiently resolve spatial coordination for general construction purposes;

- consider procurement data schedules;

- associate FM related data as part of commissioning (via COBie or similar)

- target commissioning data prior to commissioning commences; and

Fabrication phase

Once the construction models are approved, it is envisaged that installers will convert them into Fabrication Models in cases where their workflow allows for this mode of delivery (e.g. for ducts and pipework). The level of automation that can possibly be applied to this process depends on predefined, knowledge-based semantic interpretation capabilities of the fabrication software in use.

Fabrication model can be used for a variety of purposes including construction detailing, fabrication and CAM routines for manufacture.

- Construction BIMs can get converted to fabrication models whilst retaining their geometry.

- Conversion back to a BIM Construction model will be possible.

- It results in greater opportunities to explore value-adding services.

- Data extracted to exchange onto the robotic site positioning layout equipment.

- The fabrication BIMs can be uploaded to the cloud and viewed on hand held tablet devices that can extract the data on demand for the installation teams.

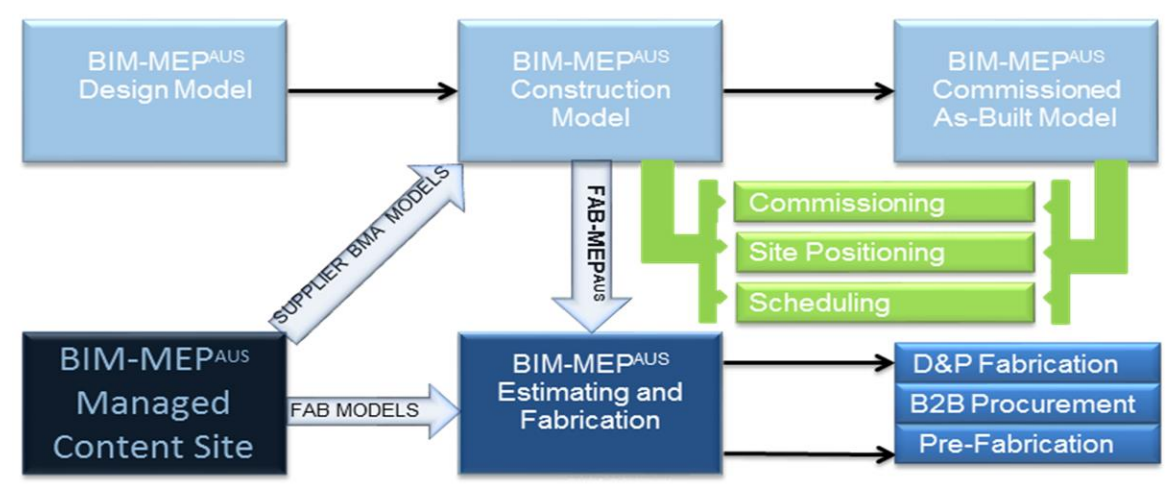

Fig.1: Schematic diagram of the BIM-MEP ${ }^{\text {AUS }}$ workflow (Source: AMCA). 


\section{Conclusions}

BIM signifies a major cultural change for Specialist Contractors as it allows them to be more linked into the design process while simultaneously maintaining tighter control over fabrication and installation processes. As a result, Specialist Contractors are empowered to provide essential value-add to life-cycle BIM as they close the gap between design intent by consultants, construction scheduling and costing by head contractors, and O\&M activities by owner/operators of a facility.

Leading Specialist Contractors are increasingly opting to link BIM to offsite fabrication. They thereby combine single or multiple trade models into virtual 'smart assemblies' to then assemble physical modules or units in controlled environments such as a factory floor. Offsite prefabrication has significant impact on time, material waste, cost and safety related matters. It reduces risk and offers more certainty about the quality of the assembly, the time required for installation, and 'just in time' deliveries. Cost savings are proving to be significant and principals and head contractors are likely to expect from their Specialist Contractors the ability to deliver such assemblies based on well-coordinated BIM.

In addition to the above, the industry is likely to experience a development towards further automation of assembly and construction with the use of robotic equipment that can directly interpret coordinated datasets provided by BIM. In order to streamline their production methods, trades can draw upon skills and expertise of parallel (e.g. car) industries where supply-chain integration and product lifecycle management (PLM) has been common for decades. Specifically, trades can draw upon the expertise from manufacturing offsite and applying a framework for prefabrication and modular strategies. Specialist Contractors and the trades thereby adopt sophisticated construction techniques and supply chain integration such as e-commerce linking or procuring equipment directly from a supplier from a BIM model. Mechanical BIM components that are set up with FM requirements in mind (using formats like COBie) will assist Specialist Contractors in bridging the gap between the construction and the operation $\&$ maintenance aspect of the facilities they work on.

\section{Acknowledgments}

This paper is partially based on an industry whitepaper the authors conceived for the Australian Institute of Architects and Consult Australia. The authors would like to acknowledge the assistance from the AMCA in authoring this paper. 


\section{References}

[1] Gallaher, M. P., O'Connor, A. C., Dettbarn, J. L., Jr., Gilday, L. T, (2004) 'Cost Analysis of Inadequate Interoperability in the U.S. Capital Facilities Industry', NIST GCR 04-867, 194

[2] Brown, K. (Ed.), (2008) 'BIM: Implications for Government', CRC Construction Innovation, Commonwealth of Australia

[3] Teicholz, P. (2013) 'Labor-Productivity Declines in the Construction Industry: Causes and Remedies (Another Look)', AECbytes Online Resource:

http://www.aecbytes.com/viewpoint/2013/issue_67.html

[4] Smith, D.K. and Tardif, M. (2009) 'Building Information Modeling: A Strategic Implementation Guide for Architects, Engineers, Constructors, and Real Estate Asset Managers', John Wiley \& Sons

[5] Taylor, J.E. and Levitt, R. (2005), Modeling Systemic Innovation in Design and Construction Networks, CIFE Technical Report \#163, Center for Integrated Facility Engineering, Stanford University

[6] General Services Administration (2007), BIM Guide For Spatial Program Validation, GSA http://www.gsa.gov/graphics/pbs/BIM_Guide_Series_02_v096.pdf Last accessed: 6 June 2014

[7] Department of Veterans Affairs (2010), The VA BIM Guide, v1.0 April 2010 http://www.cfm.va.gov/til/bim/BIMguide/, Last accessed: 6 June 2014

[8] McGraw Hill (2014), 'SmartMarket Report', The Business Value of BIM for Construction in Major Global Markets, How Contractors around the world are driving innovation with Building Information Modeling, McGraw Hill Construction

[9] Specialist Engineering Contractor (SEC) Group (2013), 'First Steps to BIM Competence, A Guide for Specialist Contractors', Specialist Engineering Contractor (SEC) Group

[10] East, E. William (2012) Construction-Operations Building information exchange (COBie), buildingSMART alliance, National Institute of building Sciences, Washington, DC. http://www.nibs.org/?page=bsa_cobie

[11] Dossick, C.S., Neff, G. and Fiore-Silfast, B. (2011), 'Implications of New Construction Technology for Western Washington Mechanical Contractors, PNCCRE Technical Report \#TR001, University of Washington

[12] Ottaviano Study of Construction Cost in NY (1995), HVAC Costs, Online Resource: http://www.fullerheating.com/fhonline/hvac/commercial/information/hvaccost.html Last accessed: 6 June 2014

[13] Eastman, C., Teicholz, P., Sacks, R. and Liston, K. 'BIM Handbook: A Guide to Building Information Modeling for Owners, Managers, Designers, Engineers and Contractors', John Wiley and Sons Ltd, Chichester

[14] Kieran, S. and Timberlake, J. (2004), 'Refabricating Architecture: How Manufacturing Methodologies are Poised to Transform Building Construction', McGraw Hill Construction

[15] ConsensuDOCS (2008), 'ConsensusDOCS 301BIM Addendum', Associated General Contractors of America (AGC)

[16] buildingSmart Australia, (2012), 'National Building Information Modelling Initiative'. Strategy: A strategy for the focussed adoption of building information modelling and related digital technologies and processes for the Australian built environment sector, Department of Industry, Innovation, Science, Research and Tertiary Education, Sydney 